\title{
Research on Moderation of Social Security Level (SSL) in Shanghai City
}

\author{
Chang-Feng Lee ${ }^{1}$ \\ ${ }^{1}$ School of Management, Shanghai University of Engineering Science, Shanghai 201620, China \\ Correspondence: Chang-Feng Lee, School of Management, Shanghai University of Engineering Science, Shanghai \\ 201620, China. E-mail: Changfeng806@126.com
}

Received: April 29, 2014

doi:10.5430/ijba.v5n3p158

\author{
Accepted: May 6, 2014 \\ Online Published: May 10, 2014 \\ URL: http://dx.doi.org/10.5430/ijba.v5n3p158
}

\begin{abstract}
Social security level (SSL) is the important indicator to reflect people's living standard in one country or one region. Using the social security theory and the measuring model of social security moderation level, the paper conducts systematic analysis on SSL moderation in Shanghai city, and further proposes some countermeasures and suggestions to perfect the SSL.
\end{abstract}

Keywords: Shanghai, SSL, moderation

\section{Introduction}

The definition of SSL is the level of enjoyment that social members have in regards to social security in a country or a region for a period of time. Normally, it is a major standard to evaluate SSL in a country by the proportion of Social Security Expenditure (SSE) in GDP. As for a region, it is the proportion of the region's security expenditure in GDP. SSL plays a significant role in social security system, which has a content of both "quality" and "quantity": in the "quality" aspect, it reviews the difference of "high" and "low" on the proportion of SSE in GDP, in the "quantity" aspect, it reflects whether the SSC matches the level of social development in a country or a region. As a result, the quality and quantity of SSL unifies each other in the concept, which ensures the social demands of public life, at the same time coordinates the development of national economy, so that it is moderate security level. Based on the SSL in Shanghai, the objective of this essay is to evaluate the city's SSL moderation by a moderate measuring model. It has an important meaning in completing the social security system of Shanghai.

\section{Analysis on Current SSL in Shanghai}

At first, it is a major step to define the scale of SSE. In China, where no statistic of consolidation has been used, the most common way is to calculate small statistic number, including social insurance, social welfare, social relief and social excellent fondle, the sum of which equals the total number of SSE, and also applies for the international practice. Figure 1 shows the SSE and GDP in Shanghai between 2008 and May, 2012.

Table 1. Statistic result on SSE and GDP in Shanghai

Unit: Billion Yuan

\begin{tabular}{cccccc}
\hline Years & $\begin{array}{c}\text { Social security } \\
\text { expenditure }\end{array}$ & Growth rate & $\begin{array}{c}\text { Gross } \\
\text { Domestic } \\
\text { Product }\end{array}$ & Growth rate & SSL \\
\hline 2008 & 364.32 & -- & 12188.85 & -- & 0.0299 \\
2009 & 457.25 & 0.255 & 13698.15 & 0.1238 & 0.0334 \\
2010 & 468.93 & 0.0256 & 15046.45 & 0.0984 & 0.0312 \\
2011 & 522.63 & 0.1145 & 17165.98 & 0.1409 & 0.0304 \\
2012 & 607.53 & 0.1624 & 19195.69 & 0.1182 & 0.0316 \\
\hline
\end{tabular}

Data sources: collected and acquired from the official websites data of China Statistical Yearbook and Shanghai Statistical Yearbook in 2009-2013.

Note: social security expenditure only includes two big items of social security and employment and medical services.

From Table 1 we can see, compared with Shanghai SSE in 2008, the SSE of 2009 was $25.8 \%$, which was 
considerably large. However the SSE of 2010 was only $2.56 \%$ more than that of 2009 . From 2010 to 2012, the total amount of Shanghai SSL showed an increasing trend year by year. Namely, the amount kept increasing, which is relevant to both growth of national economy and price level. During the 5 years, SSL stayed between 3\% and 3.4\%. The SSL decreased a little in 2010 and 2011, but on the whole, the ratio of the total assets of social security and the gross regional production demonstrated the yearly growing trend, SSL increased with the gross regional production, and the proportion of the distribution from social wealth to social security was rising.

\section{Analysis of Shanghai SSL Moderation}

Social security moderation level is an interval concept, that is, a constituted interval between the upper and the lower SSLs. SSL measuring model constructed by Professor Mu Huaizhong in Liaoning University is mostly widely used for measuring SSL moderation. Constructed on the basis of population structure theory and Cobb-Douglas production function, the model measures the SSL moderation through the model of social security burden coefficient and input distribution coefficient of labor production factor. The formula is as follows:

$$
S=S a / W \times W / G=Q \times H=0.75 \times(O *+Z+J+M) .
$$

In this formula, $\mathrm{S}$ is the SSL; Sa represents the total social security expenditure; W represents total salary income; $\mathrm{G}$ represents GDP; Q is social security burden coefficient, which is the ratio of SSE to total salary income; H is input distribution ratio coefficient of labor production factor, is the ratio of salary income to GDP, and many scholars identify $\mathrm{H}$ as $75 \%$; $\mathrm{O} *$ indicates the elderly population proportion to the total population; $\mathrm{Z}$ represents the proportion of unemployment insurance to salary income; $\mathrm{J}$ is the proportion of injury and maternity insurance to salary income; and $\mathrm{M}$ is the proportion of relief and preferential spending to the salary income. In accordance with international practices and the social security policy adopted in China, the value range of variable $\mathrm{Z}$, that is, unemployment security expenditure proportion coefficient, is $(1 \%, 1.5 \%)$; $\mathrm{J}$ is $(0.016 \%, 1.5 \%)$; $\mathrm{M}$ is $(1 \%, 1.5 \%)$. Therefore, the measuring model of upper and lower level on the moderation of SSL can be expressed as:

$$
\begin{aligned}
& S_{\text {upper limit }}=0.75 \times\left(O^{*}+Z_{\text {upper limit }}+J_{\text {upper limit }}+M_{\text {upper limit }}\right) \text {; } \\
& S_{\text {lower limit }}=0.75 \times\left(O^{*}+Z_{\text {lower limit }}+J_{\text {lower limit }}+M_{\text {lower limit }}\right) .
\end{aligned}
$$

The upper limit and lower limit of SSL in Shanghai city can be acquired through the measuring model by substituting the elderly population ratio from 2009 to 2011, and can be compared with the real SSL in Shanghai currently. See Table 2.

Table 2. Statistic result of social security moderation level in Shanghai city Unit: \%

\begin{tabular}{cccccc}
\hline Year & $\begin{array}{c}\text { The elderly } \\
\text { proportion }\end{array}$ & $\begin{array}{c}\text { Moderate } \\
\text { upper limit }\end{array}$ & $\begin{array}{c}\text { Moderate } \\
\text { lower limit }\end{array}$ & Real SSL & $\begin{array}{c}\text { Existing level } \\
\text { gap }\end{array}$ \\
\hline 2008 & 15.3 & 14.85 & 12.99 & 2.99 & -10.00 \\
2009 & 15.4 & 14.93 & 13.06 & 3.34 & -9.72 \\
2010 & 15.8 & 15.23 & 13.36 & 3.12 & -10.24 \\
2011 & 16 & 15.38 & 13.51 & 3.04 & -10.47 \\
2012 & 16.6 & 15.83 & 13.96 & 3.16 & -10.80 \\
\hline
\end{tabular}

Data sources: the elderly population data is from China Statistical Yearbook and Shanghai Statistical Yearbook (2009-2013)

Note 1. The proportion of people over the 65 years to total population in Shanghai city is chosen for the elderly population proportion

Note 2 . The existing level gap $=$ real SSL - lower limit of social security moderation level

It can be seen from data analysis in Table 2: firstly, the SSL and social security moderation level in Shanghai has simultaneous growth trend, and the gap between lower moderation limit and real level value stabilizes between $10 \%$ and $11 \%$. Secondly, Shanghai social security moderation interval in the past three years is roughly between $13 \%$ and $16 \%$, and although Shanghai SSL keeps growing, it is far from the lower moderation level and the yearly increasing gap trend between real SSL and lower moderation limit. Thirdly, both the gaps between upper and lower limit of social security moderation level and existing level in Shanghai are far greater than that of other provinces under the same caliber measurement. In this case, that would have negative impacts on the local economic development and the stability of Shanghai. 


\section{Reflection on Social Security Moderation Level of Shanghai City}

SSL presents how many economic resources are contributed to people's social security benefits in a country or a region. Generally, the SSL is rather low in Shanghai city. Table 2 reads a great gap between Shanghai's real SSL at about 3\% and the lower moderation limit of SSL at 13\%-14\%, and such large gap tends to widen year by year. With an adverse effect on economic and social development of the area, low SSL would limit the growth of domestic demand directly and impede the development of economic society if it fails to meet people's basic necessities of living.

The reasons why Shanghai SSL keeps low at current stage are of many aspects. First, nationally, the general SSL is not very high in China, which must suppress the improvement of Shanghai. By reading massive relative documents, we find that a great gap between the real SSL and its lower moderation limit still exists from the perspective of no matter the whole country or provinces. Second, as an international metropolis, Shanghai is in the key stage of industrial restructuration and innovation-driven development. During the period of economic system reformation, with the slowly improvement of Shanghai economy, the municipal finance seems to be in difficulty to secure social security financial investment under the original serious shortage of social security capital. Finally, Shanghai has serious ageing problem. According to the international general standard, when people aged 65 or above account for over $7 \%$ of the total population, the society enters the aging society and Shanghai has entered in 2000 . The Table 2 shows in 2008, the proportion of people aged 65 has reached $15.3 \%$ of the total population and in 2012 even up to $16.6 \%$. According to the formula $\mathrm{S}=0.75 \times(\mathrm{O} *+\mathrm{Z}+\mathrm{J}+\mathrm{M})$, the elderly proportion is an important influencing factor for social security moderation. Once the proportion of $\mathrm{O}^{*}$ keeps increasing, the moderation interval of social security level must keep increasing as well. Because of the fast growth of aging population in Shanghai and its higher speed than the economic growth, Shanghai SSL will always stays under the lower moderation level, and the gap is gradually expanding.

The Table 1 tells us that the growth rate of Shanghai SSL is higher than its GDP in 2009 and 2012.The growth rate of social security expenditure in 2009 reached $25.5 \%, 13.12 \%$ higher than that of GDP at the same period. In 2010, the growth rate of Shanghai GDP was 7.28\% higher than its social security level. Considering the growth situation of social security expenditure and GDP since 2008, we can draw that the average growth rate of Shanghai social security expenditure per year was $13.93 \%, 1.89 \%$ higher than the average growth rate of its GDP at the same period. In conclusion, Shanghai social security expenditure is correspondent with its economic improvement.

\section{Suggestion on Shanghai Social Security System}

The moderate balance of shanghai social security system is to make both SSL and contemporaneous social economic development adapt to endurance abilities from different aspects. According to actual SSL condition in Shanghai and its reasons, it lists following strategies and suggestions:

1). Make and implement a flexible plan timely to lengthen the retirement age. According to the analysis from social security, the retirement insurance expenditure proportion is the biggest, with highest burden. Aging problem in Shanghai is abnormal obviously, so making and implementing a flexible plan timely can effectively reduce the pressure of social security fund, which is, of course, a slow and progressive process.

2). Enlarge the coverage area of social security, and perfect social security system gradually. Firstly, we need to quicken the development of social security in countryside because the SSL dualization still exist in rural and urban Shanghai, and rural SSL has a large gap with urban SSL. It will be important for shanghai SSL if rural social security is enlarged. Secondly, the rate of joining insurance of social insurance in Shanghai is low, so it needs to include some suitable employees into social security network to increase the saving and payment capacity of social security fund. Finally, improving social security system and socialization level gradually is needed.

3). Enlarge the supporting of finance to social security and adjust financial expenditure structure. Governmental financial investment is a basic measure to promote social security system construction and improve SSL. Although SSE scale in Shanghai keeps increasing yearly, SSL proportion in total financial expenditure of the whole city is still low ( 2010 was $15.6 \%, 2011$ was $14.8 \%$ and 2012 is $15.6 \%$ ), which cannot satisfy the demand of social security development. So increasing the financial expenditure is needed to lay solid substantial foundation to realize moderation gradually. It also needs to enlarge the support on social assistance and social welfare at the same time.

4). Spread financing methods, and build financing incentives. Firstly, the government should enlarge the collection intensity to social insurance fund. Secondly, encourage individuals to set up multi-pillar and multi-story individual security system. Broaden the financing channels through many methods again, for example, transfer national asset parts which are issued at premium and the beneficial part of state-run stock right and change part proportion to social 
security funds; a part can also be taken from land transfer fee, high-profit industry and individual income tax to recovering the insufficient social fund.

5). Strengthen the effective supervision for social security fund and realize its safety and appreciation. Governments should strengthen the scientific management of social security fund, perfect the organization structure and working mechanism, and make the fund use and supervision effective, transparent, and legislative, Introduce social security fund into the capital market, and use multiple combinations to increase the return on investment of social security fund so as to realize the appreciation and decrease the gap.

6). Quicken the industry structure adjustment, make a creative and driven transformation development, and develop local economy intensively. Social security system is to develop based on certain social economic development, and SSL has a positive relation with GDP development. Therefore, the basic way of establishing suitable social security system is to develop local economy intensively so as to form a positive interaction between social security with economic development.

Generally speaking, the overall SSL in Shanghai is particularly low, and this level has continuously kept far below the moderate space, moreover, the gap shows an expand tendency year by year. In order to improve the development of Shanghai SSL, and make the level gradually up to a proper degree, we need to make some industrial structure adjustment and spare no efforts to boost economy; intensify efforts to give more government financial support to the social security, especially for the rural areas, and inch by inch change the dual structure of the social security between the urban and the rural, endeavor to expand the coverage of the social security so as to benefit more residents; improve the social security system, ensure a suitable social security system which keeps pace with the social development of Shanghai, thus we manage to secure the basic life of people and stimulate the sound and harmonious development of economy and society.

\section{References}

Hang, Tian. (2011). Analysis of SSL and its Moderation of Jiangsu Province. Regional economy, (9).

Lin, Bo. (2012). Research on Moderation of SSL. Finance and Economy, 12.

Mu, Huaizhong, \& Yan, Linlin. (2012). The Detection on Pay Level and Suitability of Fundamental Annuities National Income Redistribution. Population and Development, 18(6).

Mu, Huaizhong. (1997). Research on Social Security Moderation level. Economic Research Journal, (2).

$\mathrm{Mu}$, Huaizhong. (2003). Redistribution of National Income and Social Security Income. China Labor and Social Security Publishing House.

Tan, Xiaofeng. (2012). Research on The Suitability of Social Security Expenditure Principle. System Reform, 3.

Wang, Linlin, \& Zhang, Hui. (2013). The Suitability of the Social Security Level - The Engine of Economic Development. Economic Herald, 10.

Wang, Yuhua. (2009). Analysis of SSL and its Moderation of Zhejiang Province. Economic Forum, (16). 